\title{
Kontrol Kecepatan Motor Sepeda Listrik menggunakan Force Sensor dan Elektromiografi (EMG)
}

\author{
Jeffrey Gunawan, Muhammad Rivai, dan Tasripan \\ Departemen Teknik Elektro, Fakultas Teknologi Elektro, Institut Teknologi Sepuluh Nopember (ITS) \\ e-mail: muhammad_rivai@ee.its.ac.id
}

\begin{abstract}
Abstrak-Torque Assisted Bicycle (TAB) merupakan sebuah sepeda dengan penambahan motor listrik sebagai bantuan bagi penggunanya. Sepeda TAB ini dapat mempermudah pengguna dalam berkendara dan ramah lingkungan karena tidak menghasilkan gas emisi. Namun, sepeda TAB masih belum terlalu diminati di Indonesia. Salah satu penyebabnya ialah penggunaan sensor torsi yang mahal. Pada penelitian ini sensor tekanan dan sensor EMG digunakan untuk mengganti sensor tersebut. Sensor EMG yang digunakan memiliki keluaran antara 0 - 5V single channel dan sensor tekanan menggunakan Force Sensitive Resistor (FSR) dengan keluaran antara 0 - 3.5V. Data dari dua sensor ini digunakan untuk mengenali tingkat aktivitas otot dari pengguna dengan menggunakan metode Artifical Neural Network dan metode pembelajaran backward propagation. Dari hasil penelitian yang telah dilakukan, penempatan elektroda optimal untuk sensor EMG pada Vastus Lateralis dan FSR pada bagian medial dari telapak kaki. Dalam pengujian statis, subyek melakukan gerakan mengayuh selama 10 detik dengan beban berupa tekanan dari rem. Hasil pengujian pada empat subyek menghasilkan tingkat ketelitian deteksi aktivitas kaki sebesar $83,33 \%$. Pada pengujian dinamis di permukaan dengan 4 tingkat kemiringan berbeda, sistem mampu mendeteksi beban dengan tingkat ketelitian $75 \%$.
\end{abstract}

Kata Kunci-EMG, ANN, TAB, Sensor Tekanan, Sepeda Listrik.

\section{PENDAHULUAN}

$S^{\mathrm{E}}$ EMAKIN bertambahnya jumlah kendaraan bermotor di Indonesia merupakan salah satu isu yang terus diperhatikan oleh pemerintah. Menurut data dari BPS (Badan Pusat Statistik), di tahun 2016, terdapat 105.150.082 sepeda motor yang beredar di Indonesia. Sepeda motor lebih diminati oleh masyarakat karena pengguna tidak perlu menggunakan tenaga yang cukup besar untuk menggerakkan sepeda motor. Sepeda merupakan salah satu alternatif moda transportasi yang dapat digunakan oleh masyarakat. Namun, karena iklim Indonesia yang cenderung panas dan kondisi geografis Indonesia yang bervariasi, sepeda kurang diminati oleh masyarakat. Untuk mengatasi kekurangan ini, dikembangkanlah sebuah Torque Assisted Bicycle (TAB).

TAB merupakan sebuah sepeda dengan fitur berupa motor listrik yang membantu menggerakkan roda sepeda. Fitur ini berguna untuk membantu pengguna ketika pengguna berkendara pada medan yang terjal sehingga memerlukan tenaga lebih besar untuk mengayuh sepeda.

Salah satu masalah terkait dengan TAB ini ialah bahwa harga sepeda jenis ini masih mahal. Salah satu faktor yang menyebabkan tingginya harga sepeda ini ialah penggunaan sensor torsi untuk menentukan kapan sistem memberikan bantuan melalui motor [1]. Oleh sebab itu, dibutuhkan sensor alternatif untuk fungsi bantuan motor ini.

Pada penelitian ini dirancang sebuah mekanisme sistem kontrol motor listrik pada TAB melalui masukan dari 2 sensor, yakni sensor Elektromiografi (EMG) dan sensor tekanan. Sensor EMG berfungsi untuk mendeteksi aktivitas otot kaki yang digunakan untuk mengayuh pedal, sedangkan sensor tekanan berfungsi mendeteksi berapa besar tekanan yang diberikan kaki subyek pada pedal. Masukan dari sensor akan diolah oleh mikrokontroler, kemudian digunakan untuk menentukan apakah pengguna memerlukan bantuan dari motor. Dengan menggunakan sistem kontrol ini, pengguna diharapkan menjadi lebih nyaman dalam menggunakan sepeda karena tidak perlu mengayuh terlalu berat pada saat berada dalam medan yang terjal. Dengan dikembangkannya sistem ini diharapkan minat masyarakat terhadap sepeda listrik TAB menjadi semakin besar.

\section{PERANCANGAN SISTEM}

Perangkat keras yang digunakan meliputi sensor EMG, sensor tekanan, mikrokontroller Arduino Nano, motor DC, serta rangkaian driver motor DC. Perangkat lunak meliputi program untuk proses artificial neural network (ANN) serta program pembacaan nilai sensor pada Arduino. Gambar 1 menunjukkan perangkat keras dan perangkat lunak yang digunakan dalam sistem.
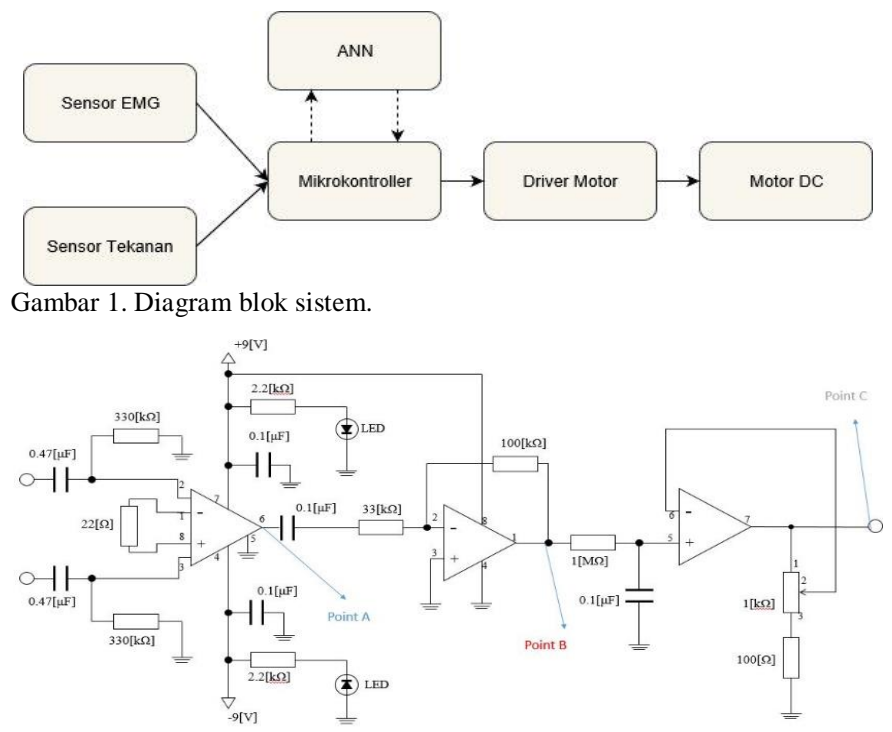

Gambar 2. Skematik rangkaian akuisisi sinyal EMG. 
Sistem akan menerima masukan dari dua sensor, yaitu sensor EMG dan sensor tekanan. Sensor EMG berfungsi mengukur aktivitas otot kaki sedangkan sensor tekanan berfungsi mengukur tekanan yang diberikan oleh kaki pada sensor yang ditempatkan di sandal. Kedua sinyal masukan ini akan diolah oleh mikrokontroller dengan menggunakan metode ANN. ANN digunakan untuk melakukan proses pembelajaran berdasarkan data yang didapatkan dari sensor pada proses akuisisi data. Setelah didapatkan nilai weight dan bias dari proses pembelajaran, nilai ini dimasukkan pada program di Arduino agar sistem mampu menentukan nilai sinyal PWM yang digunakan untuk menggerakkan motor.

\section{A. Perancangan Sensor EMG}

Rangkaian sensor EMG digunakan untuk mengetahui tingkat kinerja otot yang sedang diukur. Pengukuran dilakukan menggunakan elektroda pada permukaan kulit. Dua elektroda digunakan pada otot yang hendak diukur dan satu elektroda digunakan sebagai titik referensi pada bagian yang bertulang pada kaki. Gambar 2 merupakan skematik rangkaian yang digunakan. Rangkaian tersebut merupakan rangkaian akuisisi sinyal EMG. Sinyal masukan didapatkan dari dua elektroda yang mengukur perbedaan potensial antara dua titik dari otot yang dituju. Kemudian sinyal akan melewati sebuah high pass filter $1 \mathrm{~Hz}$ dan dikuatkan oleh sebuah penguat instrumentasi. Berikutnya sinyal akan masuk ke rangkaian active high pass filter $50 \mathrm{~Hz}$ [2]. Hasil sinyal setelah melalui bagian ini ditunjukkan pada poin B. Tahap terakhir pada rangkaian ini ialah low pass filter $1 \mathrm{~Hz}$ dan non-inverting amplifier yang gainnya dapat diatur dengan menggunakan sebuah potensiometer. Secara keseluruhan rangkaian didesain untuk menangkap sinyal EMG pada frekuensi $1-100 \mathrm{~Hz}$.

\section{B. Perancangan Sensor Tekanan}

Sensor tekanan menggunakan sebuah Force Sensitive Resistor (FSR), yakni sebuah sensor resistif yang nilai resistansinya berubah sesuai dengan beban yang diberikan padanya. Nilai resistansi FSR berbanding terbalik dengan besarnya tekanan yang diberikan padanya. Nilai hambatan pada saat tidak ada tekanan diatas $100 \mathrm{kOhm}$, sedangkan pada saat tekanan maksimum nilai resistansi sangat kecil dibawah nilai $1 \mathrm{Ohm}$. Grafik kerja dari sensor FSR ini ditunjukkan pada Gambar 3.

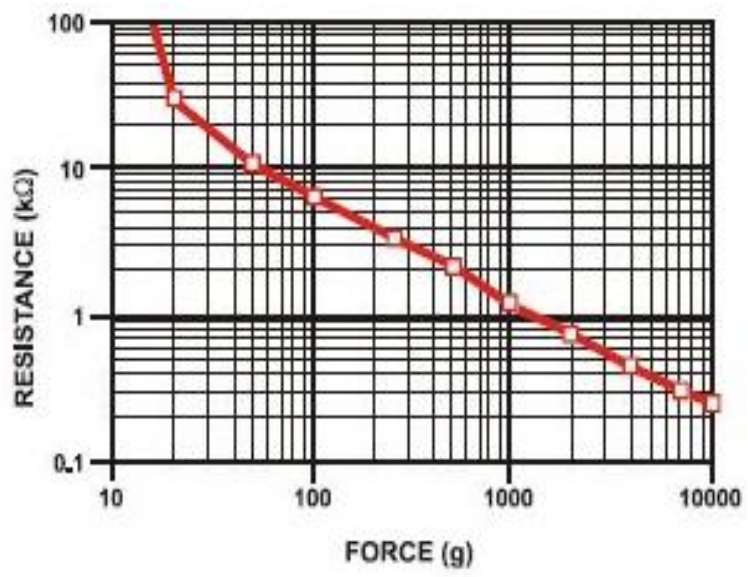

Gambar 3. Grafik kerja sensor FSR.

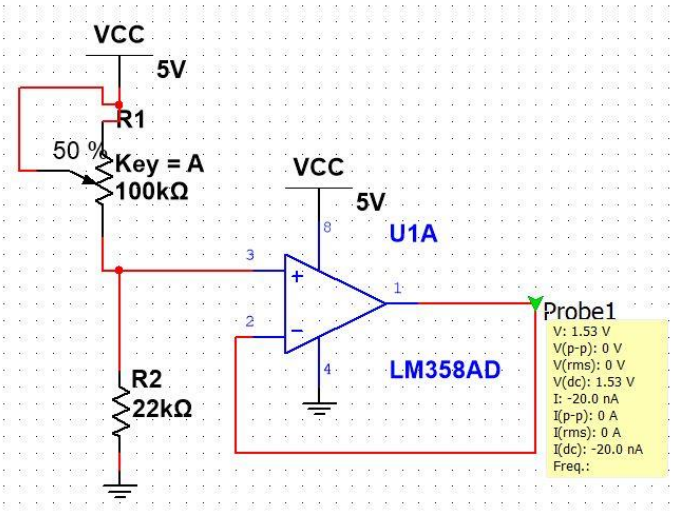

Gambar 4. Rangkaian sensor tekanan.

Rangkaian pada Gambar 4 didesain sedemikian rupa agar nilai tegangan berbanding lurus dengan besar tekanan yang diberikan pada FSR. Sehingga rentang tegangan keluaran berkisar dari $0.9-3.5 \mathrm{~V}$. Pada rangkaian ini catu daya yang digunakan sebesar 5VDC. Pada penelitian ini, sensor tekanan diletakkan pada sebuah sandal dengan FSR ditempelkan pada bagian dalam sandal. Ilustrasi dari berbagai titik tekanan pada telapak kaki manusia ditunjukkan pada Gambar 5 .

Pada penelitian sebelumnya digunakan 5 sensor untuk 5 titik tekanan pada kaki [3]. Namun, pada penelitian ini hanya digunakan satu titik saja, yakni titik nomor 5 .

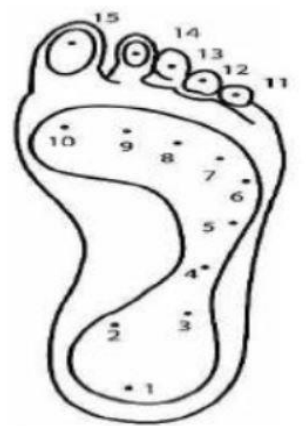

Gambar 5. Ilustrasi titik tekanan pada telapak kaki.

\section{Perancangan Perangkat Lunak Komputer}

Pembelajaran menggunakan ANN digunakan untuk mengenali tingkat aktivitas kaki subyek. ANN merupakan metode pembelajaran yang cukup sering digunakan dalam berbagai riset, seperti pengenalan suara [4], pendeteksian kualitas kesegaran daging [5], dan hidung elektronik [6]-[8]. ANN merupakan metode pembelajaran yang cocok untuk digunakan karena memiliki tingkat kesukesan yang tinggi dengan jumlah kanal yang minimum [9], [10]. Model ANN yang digunakan ialah Feedforward Multilayer Neural Network dan metode pembelajaran menggunakan algoritma Backward propagation [10]. Dalam program ANN ini terdapat beberapa tahapan dalam pengolahan data seperti yang ditunjukkan pada Gambar 6, yaitu:

1. Input Data

Pada tahap ini, pengguna memasukkan sekumpulan data yang akan digunakan dalam proses learning beserta sebuah setpoint atau target untuk tiap data tersebut.

2. Normalisasi Data

Normalisasi dilakukan untuk menskalakan nilai masukan yang diberikan dalam suatu rentang yang didefinisikan 
sebelumnya. Proses normalisasi menggunakan nilai xmin dan xmax, yakni nilai maksimum dan minimum dari keseluruhan data yang dimasukkan. Berikut merupakan rumus dalam menghitung nilai normalisasi:

$$
\text { norm }=\frac{x-x \min }{x \max -x \min }
$$

$x$ menunjukkan nilai sensor yang mana nilai tersebut diskalakan kedalam skala antara nol dan satu.

\section{Feedforward Propagation}

Pada tahap ini, proses pembelajaran pada jaringan dimulai. Nilai masukan yang telah dinormalisasi akan diolah kedalam suatu jaringan hidden layer dengan menggunakan sebuah fungsi aktivasi. Fungsi aktivasi yang digunakan pada program ini adalah fungsi log sigmoid karena fungsi log sigmoid ini merupakan fungsi yang mendekati cara kerja otak manusia [6]. 4. Perhitungan Eror

Pada tahap ini setelah menentukan keluaran untuk tiap jumlah data yang dimasukkan, eror dihitung dengan rumus sebagai berikut:

$$
\text { Eror }=\text { Setpoint }- \text { Output }
$$

Kemudian nilai eror ini akan digunakan untuk melakukan fungsi pembelajaran backpropagation.

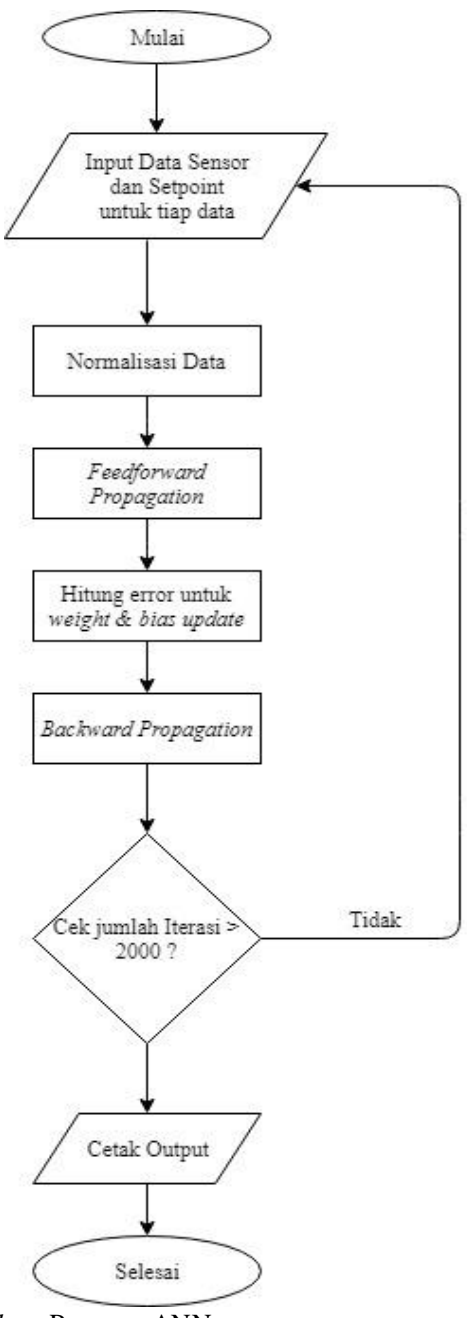

Gambar 6. Flowchart Program ANN.

\section{Backward Propagation}

Metode pembelajaran backpropagation dilakukan untuk mengubah nilai parameter weight dan bias berdasarkan dari nilai eror yang didapatkan dalam perhitungan sebelumnya. Dalam perhitungan ini terdapat beberapa parameter yang menentukan proses pembelajaran serta update parameter berikutnya:

$$
\begin{gathered}
s^{M}=-2 * F^{M}\left(n^{M}\right) *(t-a) \\
s^{m}=F^{m}\left(n^{m}\right) *\left(w^{m+1}\right)^{T} * s^{m+1}
\end{gathered}
$$

nilai $m=\mathrm{M}-1, \ldots, 2,1$. Rumus tersebut digunakan untuk menghitung nilai sensitivitas yang akan digunakan untuk update parameter nilai weight dan bias. Terdapat rumus untuk update parameter dari weight dan bias sendiri, yakni:

$$
\begin{aligned}
& w^{m}(k+1)=w^{m}(k)-\alpha * s^{m}\left(\alpha^{m-1}\right)^{T} \\
& b^{m}(k+1)=b^{m}(k)-\alpha * s^{m}
\end{aligned}
$$

Simbol alfa pada rumus diatas adalah learning rate. Jika nilai variabel ini semakin tinggi maka nilai weight dan bias mengalami perubahan yang semakin cepat, namun mengalami penurunan dalam akurasi hasil akhir yang didapatkan.

6. Pengulangan Iterasi

Proses pembelajaran akan berlangsung sebanyak jumlah iterasi yang sudah dispesifikasikan sebelumnya. Untuk program ini, jumlah iterasi dispesifikasikan sebesar 2000 kali untuk tiap set data $n$ yang dimasukkan kedalam program. Kemudian program akan mengecek apakah jumlah iterasi yang dilakukan selama proses pembelajaran sudah tercapai.

Kedua nilai ini akan diimplementasikan dalam perangkat lunak pada Arduino agar mikrokontroller mampu mengenali data dari sensor dan memberikan nilai sinyal PWM berdasarkan data pengolahan.

\section{Perancangan Perangkat Lunak Arduino}

Perangkat lunak pada Arduino dirancang untuk membaca masukan dari kedua sensor, yaitu sensor EMG dan sensor tekanan. Kemudian mengolah data tersebut menggunakan metode propagasi feedforward ANN. Nilai weight dan bias didapatkan dari proses pembelajaran yang dilakukan sebelumnya pada komputer. Kemudian Arduino menghasilkan sinyal PWM berdasarkan kontrol proporsional yang digunakan untuk mengatur kecepatan motor listrik pada TAB.

\section{HASIL DAN ANALISA}

\section{A. Pengujian Sensor EMG pada Gerakan Cycling}

Pengujian Sensor EMG dilakukan untuk mengetahui perbedaan amplitudo sinyal EMG dengan mengukur besarnya tegangan yang dihasilkan pada 3 kondisi beban yang telah ditentukan, yaitu beban minimal, setengah beban, dan beban maksimum. Beban diberikan dengan penggunaan tuas rem pada ban belakang sepeda. Kategori tanpa beban merupakan hasil pengukuran saat rem tidak ditekan, setengah beban merupakan hasil pengukuran saat pengguna menekan tuas rem sejauh 4,5 cm dari titik normal sedangkan kategori beban penuh merupakan hasil ketika tuas rem ditekan $6 \mathrm{~cm}$ dari titik normal. Pengukuran dilakukan selama 10 detik dengan gerakan mengayuh pada kecepatan konstan di tiga kategori beban yang telah ditentukan sebelumnya. Dalam pengukuran 
ini digunakan 3 buah elektroda, dengan 2 elektroda untuk titik V1 dan V2, yaitu otot yang hendak dituju, dan 1 elektroda pada titik REF, yaitu titik pada anggota tubuh yang memiliki bagian tulang menonjol. Gambar 7 merupakan peletakan elektroda pada otot Vastus Lateralis dan Gastrocnemius Soleus.

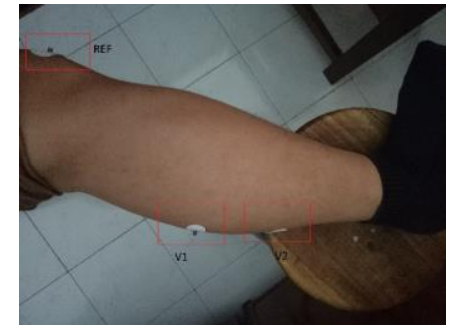

(a)

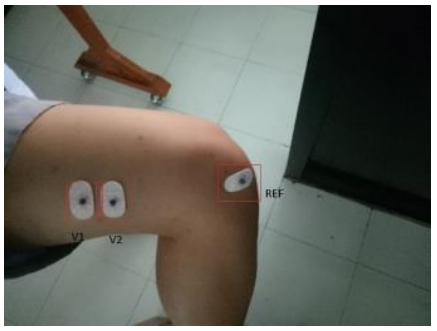

(b)
Gambar 7 (a) Elektroda di Vastus Lateralis dan (b) Elektroda di Gastrocnemius dan Soleus

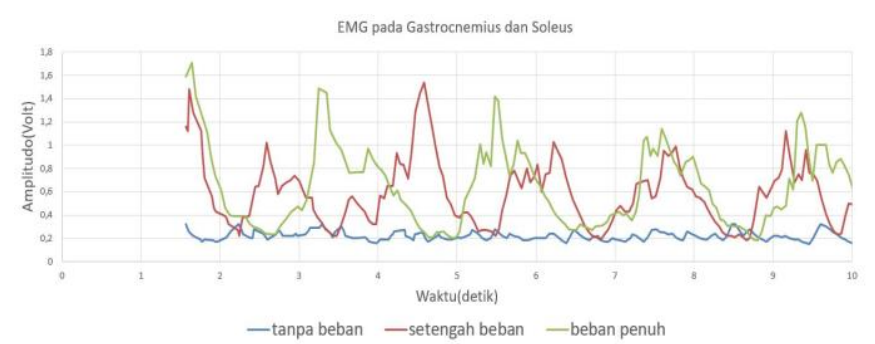

Gambar 8. Pengukuran EMG pada Otot Gastrocnemius dan Soleus.

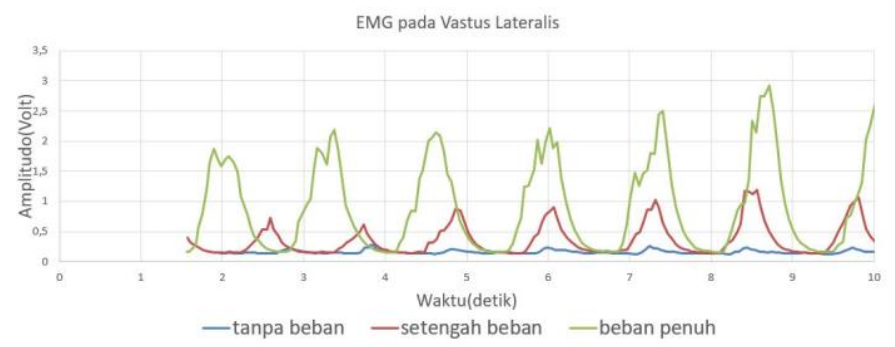

Gambar 9. Pengukuran EMG pada Otot Vastus Lateralis.

Pada penelitian ini, dua titik di kaki tersebut dipilih karena merupakan otot yang dominan ketika mengayuh sepeda [11]. Titik V1 dan V2 merupakan titik akuisisi sinyal EMG yang akan dimasukkan ke rangkaian sedangkan titik REF merupakan titik referensi sinyal, yaitu bagian dari kaki yang keras (tulang menonjol) dan tidak terdapat otot. Hasil pengukuran sensor EMG pada dua lokasi pengukuran ditunjukkan pada Gambar 8 dan 9. Dapat dilihat bahwa grafik EMG dari otot Vastus Lateralis menunjukkan hasil yang lebih baik karena pola sinyal yang cukup konsisten selama sepuluh detik pengukuran.

\section{B. Pengujian Gabungan Sensor EMG dan Tekanan}

Pada tahap ini dilakukan pengujian gerakan mengayuh dengan menggunakan sensor tekanan dan sensor EMG secara bersamaan. Kondisi pengujian masih sama dengan tahap sebelumnya dan peletakan sensor EMG pada otot Vastus Lateralis dan sensor tekanan pada bagian medial dari telapak kaki. Hasil pengukuran kedua sensor ditunjukkan pada Gambar 10, 11, dan 12.

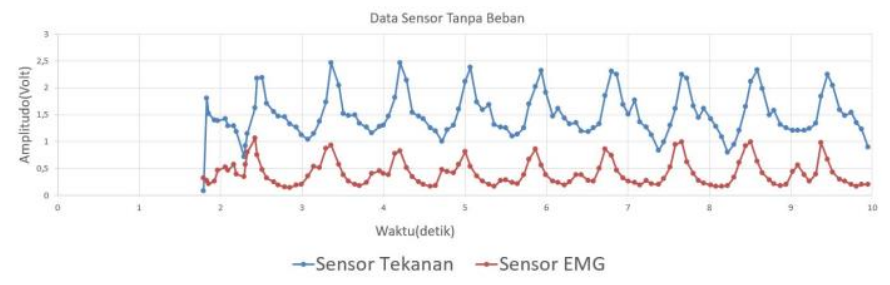

Gambar 10. Pengukuran pada Kondisi Tanpa Beban

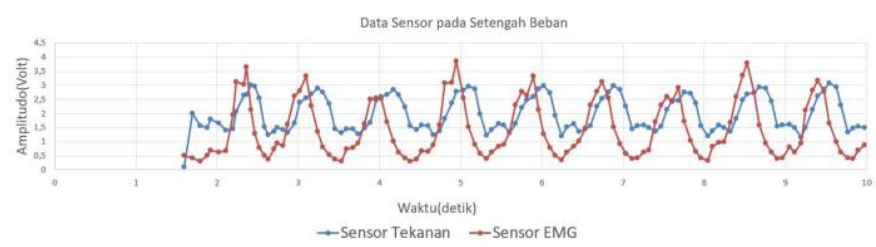

Gambar 11. Pengukuran pada Kondisi Setengah Beban

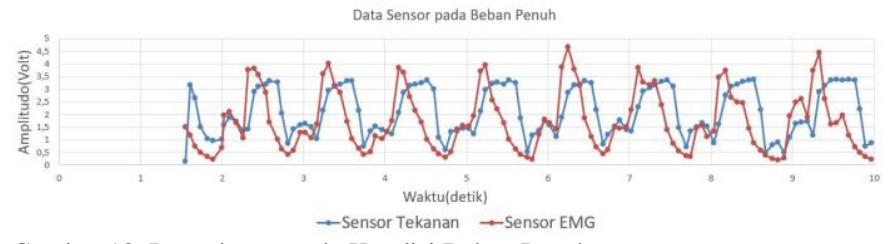

Gambar 12. Pengukuran pada Kondisi Beban Penuh

Dari tiga grafik hasil akuisisi data tersebut dapat dilihat bahwa data sensor yang didapatkan pada tiga kondisi beban yang berbeda memiliki amplitudo yang berbeda-beda. Tahap pengujian ini dilakukan selama 3 hari yang berbeda untuk merekam data sensor pada tiga hari. Data ini akan digunakan untuk tahap berikutnya, yaitu tahap pembelajaran ANN.

\section{Pengujian Sistem Pembelajaran ANN}

Program pembelajaran ANN ditulis dan di-compile pada laptop, sehingga proses pembelajaran berjalan secara terpisah dari mikrokontroller. Untuk mendapatkan representasi dari sinyal yang direkam selama 10 detik digunakan metode moving average filter (MAV) dengan orde 60. Pada riset sebelumnya telah digunakan filter MAV orde 12 ini untuk mengolah sinyal EMG lebih lanjut [12]. Kemudian, perlu diberikan suatu setpoint dalam pembelajaran ANN bagi tiap data yang diberikan pada masukannya. Data yang digunakan dalam proses pembelajaran terbagi menjadi 2 jenis dengan perbedaan terletak pada tempat peletakan elektroda untuk sensor EMG. Dari hasil pembelajaran akan dihitung nilai eror untuk menentukan penempatan elektroda yang lebih optimal untuk digunakan. Data A adalah data sensor EMG pada otot Gastrocnemius dan Soleus sedangkan data B adalah data sensor EMG pada otot Vastus Lateralis. Untuk menentukan data yang lebih baik antara data pembelajaran A dan B maka digunakan analisis sum square error (SSE). Berikut merupakan rumus yang digunakan untuk menghitung SSE:

$$
S S E=\frac{1}{N} \sum_{i=0}^{N}(y-\hat{y})^{2}
$$

variabel y merupakan keluaran program untuk data ke- $i, \hat{y}$ merupakan setpoint untuk data ke-i, dan $\mathrm{N}$ merupakan jumlah data pembelajaran. Hasil perhitungan nilai SSE untuk data A dan data B ditunjukkan pada Tabel 1 dan 2: 
Tabel 1.

Nilai error untuk data A

\begin{tabular}{lllll}
\hline \hline & Setpoint & Hasil Learning & Square Error & SSE \\
\hline Data 1 & 0 & 0,229 & 0,052441 & 0,046323 \\
& 0,5 & 0,469 & 0,000961 & \\
& 1 & 1,23 & 0,0529 & \\
Data 2 & 0 & 0,1727 & 0,02982529 & \\
& 0,5 & 0,5332 & 0,00110224 & \\
& 1 & 0,949 & 0,002601 & \\
Data 3 & 0 & 0,082 & 0,006724 & \\
& 0,5 & 0,31 & 0,0361 & \\
& 1 & 0,516 & 0,234256 & \\
\hline \hline
\end{tabular}

Tabel 2.

Nilai error untuk data B

\begin{tabular}{llllc}
\hline \hline & Setpoint & Hasil Learning & Square Error & SSE \\
\hline Data 1 & 0 & $-0,0026$ & 0,00000676 & 0,045733 \\
& 0,5 & 0,688 & 0,035344 & \\
& 1 & 0,93 & 0,0049 & \\
Data 2 & 0 & 0,153 & 0,023409 & \\
& 0,5 & 0,852 & 0,123904 & \\
& 1 & 0,744 & 0,065536 & \\
Data 3 & 0 & $-0,089$ & 0,007921 & \\
& 0,5 & 0,607 & 0,011449 & \\
& 1 & 0,627 & 0,139129 & \\
\hline \hline
\end{tabular}

Dari Tabel 1 dan 2 dapat dibandingkan bahwa data B menghasilkan nilai eror yang lebih kecil dibandingkan dengan data A. Maka untuk tahap pengujian akhir, otot yang digunakan untuk peletakan sensor EMG ialah otot Vastus Lateralis.

\section{Pengujian Akhir Kondisi Statis}

Pengujian keseluruhan alat pada kondisi statis dilakukan agar mengetahui performa alat sebelum dilakukan pengujian dinamis yaitu pengujian pada permukaan lantai. Pengujian alat pada kondisi statis dilakukan dengan memberikan beban dari rem, kemudian mengamati perubahan yang terjadi pada indikator LED pada alat. Kriteria pemberian beban pada subyek masih sama dengan pengujian A. Hasil keluaran ANN digunakan sebagai sinyal eror untuk menentukan besarnya sinyal PWM yang akan menggerakkan motor DC. Evaluasi terhadap sistem dilakukan dengan mengamati indikator lampu LED yang terdapat pada sistem. Terdapat 3 LED sebagai indikator tingkat beban yang diberikan pada subyek. LED 1 menyala jika hasil ANN berada dibawah 0,5 atau beban minimal, LED 2 menyala jika hasil ANN berada di antara 0,5 dan 1,0 atau beban setengah maksimum, dan LED 3 menyala jika hasil ANN lebih besar daripada 1 atau mengindikasikan beban maksimum. Ilustrasi pengujian dapat dilihat pada Gambar 13.

Tabel 3.

Data pengujian akhir pada kondisi statis

\begin{tabular}{ccc}
\hline \hline Subyek & Beban & Indikator \\
\hline Subyek 1 & Minimal & LED 1 \\
& Setengah & LED 2 \\
& Maksimal & LED 3 \\
Subyek 2 & Minimal & LED 1 \\
& Setengah & LED 2 \\
& Maksimal & LED 3 \\
Subyek 3 & Minimal & LED 1 \\
& Setengah & LED 1 \\
& Maksimal & LED 3 \\
Subyek 4 & Minimal & LED 1 \\
& Setengah & LED 1 \\
& Maksimal & LED 3 \\
\hline \hline
\end{tabular}

Dari Tabel 3 dapat dilihat bahwa sistem mampu mendeteksi tiga tingkat aktivitas kaki yang berbeda pada subyek 1 dan 2 dengan akurat, namun lain halnya dengan subyek 3 dan 4. Sehingga, dapat disimpulkan bahwa pada tahap pengujian ini, sistem memiliki tingkat ketelitian deteksi beban sebesar $83,33 \%$.

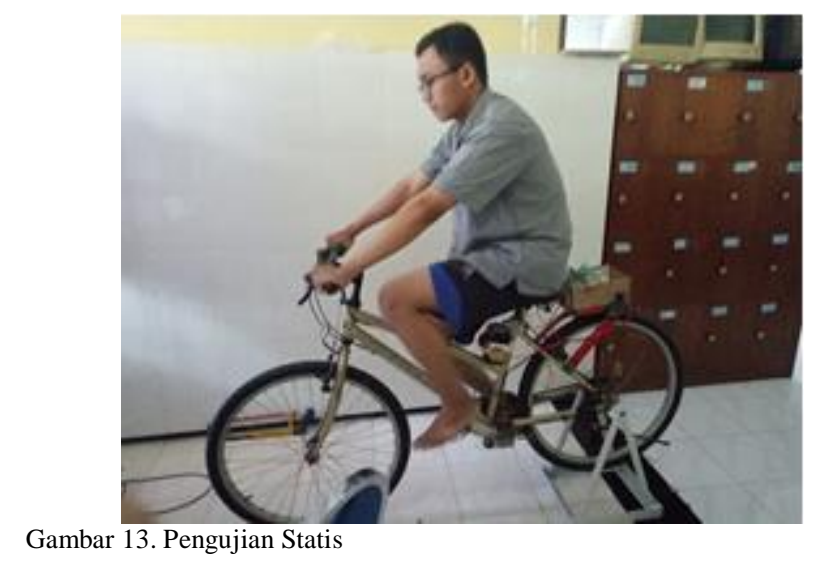

Tabel 4.

Data pengujian akhir pada kondisi dinamis

\begin{tabular}{cccc}
\hline \hline $\begin{array}{c}\text { Derajat } \\
\text { Kemiringan }\left({ }^{\circ}\right)\end{array}$ & Respon Hari I & Respon Hari II & Respon Hari III \\
\hline 0 & 1 & 1 & 1 \\
10 & 3 & 3 & 2 \\
15 & 2 & 3 & 2 \\
20 & 3 & 3 & 3 \\
\hline \hline
\end{tabular}

E. Pengujian Akhir Kondisi Dinamis

Pada tahap ini dilakukan pengujian akhir pada permukaan lantai serta tanjakan dengan 4 derajat kemiringan yang diatur untuk mengetahui respon alat. Dalam pengujian ini digunakan 4 macam sudut kemiringan permukaan lantai, yaitu $0^{\circ}, 10^{\circ}$, $15^{\circ}$, dan $20^{\circ}$. Pada pengujian ini ditentukan bahwa sudut $0^{\circ}$ menandakan beban minimum, sudut $10^{\circ}$ dan $15^{\circ}$ menandakan beban setengah, dan sudut $20^{\circ}$ menandakan beban maksimum. Hasil dari pengujian ini ditunjukkan pada Tabel 4. Dari tabel tersebut dapat dilihat data hasil pengujian dinamis pada permukaan rata serta tanjakan dengan tiga sudut kemiringan.

Hasil pengujian pada tingkat kemiringan $0^{\circ}$ dan $20^{\circ}$ menunjukkan hasil yang konsisten dalam tiga kali pengujian. Namun, hasil pengujian pada tingkat kemiringan $10^{\circ}$ dan $15^{\circ}$ menunjukkan hasil yang tak konsisten karena indikator LED yang menyala tak konsisten. Adapun pada kedua tingkat kemiringan ini, indikator yang seharusnya menyala ialah indikator LED 2, karena beban yang diberikan masih kurang dari beban pada tingkat kemiringan $20^{\circ}$. Sehingga secara keseluruhan dapat ditarik kesimpulan bahwa dari tiga kali pengujian pada empat titik kemiringan yang berbeda, sistem mampu mendeteksi beban dengan tingkat akurasi rata-rata $75 \%$.

\section{KESIMPULAN}

Pada penelitian ini, sebuah purwarupa Torque Assisted Bicycle telah diwujudkan dengan menggunakan sensor EMG dan sensor tekanan sebagai piranti masukan. Mikrokontroler Arduino digunakan untuk mengolah masukan dari dua sensor tersebut. Sensor EMG yang digunakan memiliki rentang 
frekuensi $1-100 \mathrm{~Hz}$ dan penguatan sebesar 7.568x hingga 83.250x. Penempatan elektroda EMG yang optimal terletak pada otot vastus lateralis sedangkan penempatan FSR yang optimal terletak pada bagian medial kaki. Hasil pengujian menunjukkan bahwa sistem ini memiliki tingkat kesalahan deteksi beban sebesar $8,93 \%$ pada pengujian menggunakan dua himpunan data. Pada pengujian statis, sistem mampu mendeteksi beban pada empat subyek dengan tingkat ketelitian 83,33\%, sedangkan pada pengujian dinamis di permukaan lantai, sistem mampu mendeteksi beban pada subyek dengan tingkat ketelitian rata-rata $75 \%$.

\section{DAFTAR PUSTAKA}

[1] N. Fukushima dan Y. Fujimoto, "Estimation of pedaling torque for electric power-assisted bicycle on slope environment," 2017, hlm. $1682-1687$.

[2] A. Hanafusa dan T. Shimizu, "Development of EMG Measurement System Aimed to Control Assisted Device," Trans. Jpn. Soc. Med. Biol. Eng., vol. 52, hlm. O-32-O-33, Agu 2014.

[3] P. S. Malvade, A. K. Joshi, dan S. P. Madhe, "IoT based monitoring of foot pressure using FSR sensor," 2017, hlm. 0635-0639.

[4] F. Budiman, M. A. Nursyeha, M. Rivai, dan . S., "Pengenalan Suara Burung Menggunakan Mel Frequency Cepstrum Coefficient dan Jaringan Syaraf Tiruan pada Sistem Pengusir Hama Burung," J. Nas. Tek. ELEKTRO, vol. 5, no. 1, Mar 2016
[5] V. S. Kartika, M. Rivai, dan D. Purwanto, "Spoiled meat classification using semiconductor gas sensors, image processing and neural network," 2018, hlm. 418-423.

[6] H. Widyantara, M. Rivai, dan D. Purwanto, "Implementation Analog Neural Network for Electronic Nose using Field Programable Analog Arrays (FPAA)," Int. J. Electr. Comput. Eng. IJECE, vol. 2, no. 6, Des 2012.

[7] M. Rivai, A. Arifin, dan E. I. Agustin, "Mixed vapour identification using partition column-QCMs and Artificial Neural Network,” 2016, hlm. 172-177.

[8] D. S. A. Pambudi, M. Rivai, dan A. Arifin, "Detection of organic solvent compounds using optical fiber interferometer array and neural network pattern recognition," 2018, hlm. 477-482.

[9] S. Shin, J. Jung, dan Y. T. Kim, "A study of an EMG-based authentication algorithm using an artificial neural network," dalam 2017 IEEE SENSORS, 2017, hlm. 1-3.

[10] C. Calderon-Cordova, C. Ramirez, V. Barros, P. A. Quezada-Sarmiento, dan L. Barba-Guaman, "EMG signal patterns recognition based on feedforward Artificial Neural Network applied to robotic prosthesis myoelectric control," 2016, hlm. 868-875.

[11] T. Tokuyasu, S. Kushizaki, S. Matsumoto, dan T. Kitawaki, "Development of automatic positioning system for bicycle saddle based on lower limb's EMG signals during pedaling motion," 2013, hlm. 2732.

[12] D. M. Sales, P. C. Galinho, P. F. Miguel, T. V. Duarte, dan F. Jo\&atilde;o, "Multimodal User Interfaces to Improve Social Integration of Elderly and Mobility Impaired," Stud. Health Technol. Inform., hlm. 14-25, 2012. 